Revista de Economia Política, vol. 32, no 2 (127), pp. 188-204, abril-junho/2012

\title{
Reciprocidade implícita e crescimento na economia internacional: uma perspectiva estruturalista
}

\author{
MARIO CIMOLI \\ GABRIEL PORCILE \\ GUILHERME SOUZA E SILVA*
}

Implicit reciprocity and growth in the international economy: a structuralist perspective. This paper discusses some of the structuralist ideas about international coordination and growth in an international system formed by countries whose productive structures and technological capabilities are strongly asymmetric. These ideas are formalized taking as a point of departure the Keynesian Balance-of-Payments constrained growth model with two countries. To this model is added a function (based on the catching up literature) in which the income elasticity of the demand for exports and imports depends on the technology gap. The model allows for discussing the inter-relations between the fiscal and the industrial and technological policies. It also allows for finding the rate of growth of autonomous expenditure in the periphery which ensures that it will use all the foreign exchange it earns in promoting economic growth (the principle of "automatic reciprocity").

Keywords: structuralist macroeconomics; economic growth; innovation and technologic diffusion.

JEL Classification: F41; F43; O54

\footnotetext{
* Respectivamente, Divisão de Desenvolvimento Produtivo e Empresarial, CEPAL - Nações Unidas e professor da Universidade de Veneza. E-mail: mario.cimoli@cepal.org CEPAL; Division de Desarrollo Productivo y Empresarial, Departamento de Economia-UFPR. E-mail: porcile@ufpr.br; Mestre em Desenvolvimento Econômico pela Universidade Federal do Paraná (UFPR). E-mail: guilherme.ricardo@ gmail.com. $\mathrm{O}$ artigo representa as ideias dos autores, mas não necessariamente a opinião das instituições em que trabalham. Submetido: 2/Fevereiro/2009; Aprovado: 18/Junho/2010.
} 


\section{INTRODUÇÃO}

Este artigo discute alguns aspectos das interações tecnológicas e de comércio entre duas economias com diferentes graus de desenvolvimento, o Norte e o Sul, a partir de uma perspectiva estruturalista. Mais especificamente, consideramos como ponto de partida as ideias de Raul Prebisch, em particular sua percepção de que o comércio internacional é um fator chave para o crescimento, tanto do Norte quanto do Sul, mas que seus benefícios requerem a cooperação internacional para se tornarem efetivos. Na sua vida pública, Prebisch insistiu na necessidade de construir instituições de coordenação internacional, através das quais os processos de mudança estrutural e de diversificação das exportações do Sul fossem estimulados. Ele via o comércio internacional como um grande jogo de soma positiva, cujas regras deviam ser negociadas e fundamentadas em instituições - e não apenas no livre jogo do mercado. O resultado disso seriam taxas mais altas de crescimento, tanto no Norte quanto no Sul (ou no centro e na periferia, conforme a linguagem do estruturalismo latino-americano).

Para Prebisch, um ponto relevante a ser considerado era que a periferia oferecia a denominada "reciprocidade implícita", isto é, em função da restrição externa ao crescimento, todas as divisas que a periferia captava seriam transformadas em maiores importações. Dessa forma, a cooperação do centro para estimular as exportações periféricas conduziria a maiores exportações do próprio centro e a um maior crescimento internacional.

As ideias estruturalistas (da existência de um espaço de crescimento conjunto e de reciprocidade implícita) são recuperadas neste trabalho; além disso, são formalizadas num modelo simples, que combina as perspectivas keynesiana e schumpeteriana. A estrutura básica do modelo é keynesiana: a demanda externa, e em particular a expansão das exportações, é vista como determinante-chave do crescimento. Ao mesmo tempo, essa demanda depende da competitividade internacional, que se fundamenta na dinâmica do aprendizado tecnológico, como sugerido pela literatura schumpeteriana do hiato tecnológico. Existe entre Norte e Sul um fluxo de comércio, mas também um fluxo de tecnologia que se origina no Norte, mais próximo da fronteira tecnológica. A capacidade do Sul de reduzir a distância tecnológica com o Norte define sua participação no comércio mundial e sua capacidade de crescer com equilíbrio externo. Argumentar-se-á que o modelo proposto oferece perspectivas interessantes sobre o vínculo entre política comercial e crescimento internacional, mas também sobre os possíveis efeitos de políticas fiscais expansionistas num contexto de interdependência comercial e tecnológica.

O trabalho está dividido em cinco seções, incluindo a introdução e as conclusões. A segunda seção apresenta uma discussão muito resumida das ideias de Raul Prebisch, no que diz respeito ao comércio internacional, exportações e crescimento econômico. A terceira seção resume o modelo de crescimento com restrição no balanço de pagamentos para dois países, desenvolvido por McCombie e Thirlwall (1994, cap. 7). Em seguida é feita a conexão entre o modelo formal e as ideias de Prebisch, apresentando alguns exercícios sobre mudanças na política fiscal e a 
mudança estrutural. Na quarta seção desenvolve-se um modelo ampliado incluindo o progresso tecnológico, tornando a relação entre as elasticidades-renda das importações dos países uma função do hiato tecnológico existente entre eles. Essa seção também discute qual é a taxa de crescimento autônomo no Sul compatível com o equilíbrio externo, e que garante a reciprocidade implícita.

\section{COMÉRCIO INTERNACIONAL E CRESCIMENTO NA PERSPECTIVA ESTRUTURALISTA}

Raul Prebisch foi o fundador e um dos mais destacados economistas da CEPAL (Comissão Econômica para a América Latina e o Caribe), tendo formulado as linhas básicas do pensamento estruturalista sobre desenvolvimento econômico ${ }^{1}$. Prebisch identificava a restrição externa como uma barreira crucial ao crescimento sustentando na América Latina. Essa restrição, por sua vez, vinculava-se ao tema do relativo atraso tecnológico da região, que se refletia num padrão de especialização pouco dinâmico.

Com efeito, Prebisch (1963) dividia os países em duas categorias, centro e periferia. Os países do centro seriam aqueles onde o progresso tecnológico avançou mais rapidamente e com maior intensidade, e que hoje são os países industrializados. Os países periféricos seriam o resultado do processo lento e desigual de difusão tecnológica desde os centros, mostrando uma forte heterogeneidade entre setores (em termos da produtividade do trabalho), baixo grau de diversificação produtiva e uma parcela importante da força de trabalho em setores de produtividade muito reduzida. Esta visão corresponde à ideia de um sistema econômico mundial polarizado em função de assimetrias tecnológicas e dos efeitos dessas assimetrias sobre a estrutura produtiva e o dinamismo exportador.

Prebisch ${ }^{2}$ identificava alguns aspectos relevantes no comportamento do sistema centro-periferia, com fortes implicações para o desenvolvimento econômico. Entre eles podemos citar, em primeiro lugar, a percepção de que o crescimento do centro se caracteriza por sua natureza centrípeta, ao diversificar constantemente os bens industriais que produz à medida que expande a demanda. Em segundo lugar, a noção de que a maior parte do comércio e dos investimentos concentra-se nos próprios centros. Para isso contribui a limitada propagação do progresso técnico até a periferia, que faz com que esta seja incapaz de competir efetivamente nas atividades dinâmicas que lideram a diversificação. $\mathrm{O}$ resultado dessa incapacidade é a especialização periférica em produtos e bens primários ou em bens industriais cuja demanda responde muito debilmente à expansão da renda. Finalmente, para que a periferia conseguisse absorver a força de trabalho desocupada ou ocupada em atividades de muito baixa produtividade, seriam necessárias taxas muito eleva-

\footnotetext{
${ }^{1}$ Uma discussão rigorosa e detalhada das ideias da CEPAL encontra-se em Rodriguez (1977, 1980, 2007).

${ }^{2}$ Ver também Prebisch (1981).
} 
das de acumulação de capital, dada a importância do setor de subsistência no emprego total.

Em suma, o crescimento da periferia resulta assim limitado pelo baixo crescimento de suas exportações em comparação com o aumento das importações, reflexo de uma estrutura produtiva pouco diversificada e com baixa capacidade tecnológica. Em outros termos, a elasticidade-renda das exportações é muito baixa quando comparada com a elasticidade-renda das importações. Como destaca Ocampo (2001):

Na visão de Prebisch, há uma tendência de especialização nos países industrializados em produtos de alta elasticidade-renda e nos periféricos aqueles de baixa elasticidade-renda (matérias-primas e manufaturas), que se reflete em última análise em uma tendência a divergência nos ritmos de crescimento e/ou a aparição de problemas no balanço de pagamentos dos periféricos, isto é, um estrangulamento externo [...].

No pensamento de Prebisch, o centro deveria facilitar as exportações periféricas, já que a última transforma todas suas exportações em importações, imprescindíveis para sustentar as elevadas taxas de acumulação requeridas pela absorção do subemprego. Nessa perspectiva, a periferia oferece uma espécie de reciprocidade automática, já que suas exportações automaticamente se traduzem em importações, sem reduzir a demanda efetiva no centro. No longo prazo, uma política de maior abertura no centro para as exportações da periferia corresponderia a uma resposta racional capaz de promover a divisão internacional do trabalho e gerar maiores benefícios tanto para o centro como para a periferia.

Prebisch mostrava-se extremamente preocupado pelos problemas de baixa competitividade da periferia, dado o tipo de especialização predominante, concentrada, como mencionado, em atividades de baixa elasticidade-renda da demanda. Nas suas próprias palavras (1963):

Só existem duas formas de corrigir gradualmente esta disparidade de elasticidades: exportar outros bens aos centros, além dos tradicionais, a fim de poder importar bens que não são possíveis de se produzir internamente [...], ou aumentar o ritmo de produção interna para alcançar desta maneira aquilo que por falta de recursos não é possível importar. Eu considero que o primeiro é mais conveniente [...].

Prebisch considerava a expansão das exportações como o caminho mais eficiente para promover o crescimento, e a substituição de importações como um "second best", a ser usado quando as condições internacionais fossem negativas, ou quando uma especialização pouco dinâmica tornava impossível expandir as exportações no ritmo necessário para pagar pelas importações. Nessa perspectiva estava presente a ideia de que as forças que mudam o padrão de especialização agem de forma muito lenta para garantir que o ajuste sempre acontecesse pela via do comércio, algo que a literatura posterior sobre path dependency e a inércia das capacidades tecnológicas viria a confirmar (Cimoli e Porcile, 2009). 
Com efeito, o processo de aprendizado tem uma série de características que podem ser resumidas da seguinte forma: i) exige tempo real e está sujeito a processos de path dependency, pelos quais a trajetória de aprendizado presente depende das capacidades e das trajetórias seguidas no passado (só é possível aprender em torno da base tecnológica existente e da experiência acumulada); ii) existem complementaridades entre as capacidades produtivas e tecnológicas entre ramos e atividades, de tal forma que as externalidades e os retornos crescentes desempenham um papel muito importante; iii) o aprendizado depende de conhecimentos tácitos associados à experiência e que não podem ser adequadamente transferidos através de manuais ou outras formas codificadas de divulgação de conhecimentos; iv) tudo isso implica uma considerável inércia nas capacidades tecnológicas e no padrão de especialização, que não pode ser mudada sem políticas proativas em favor da mudança estrutural (Amsden, 1989; Bell, 2006; Cimoli et al., 2010).

O objetivo de longo prazo devia apontar na direção da diversificação das exportações e de uma política mais ativa nesse campo, com apoio das instituições do comércio internacional. Nas próximas seções, as ideias estruturalistas sobre reciprocidade implícita e os vínculos entre tecnologia, padrão de especialização e taxas de crescimento relativas, serão analisadas no marco de um modelo formal centro-periferia, dando destaque ao papel das instituições no crescimento em nível internacional.

\section{O MODELO DE CRESCIMENTO COM RESTRIÇÃO EXTERNA DE DOIS PAÍSES}

\section{O modelo básico}

Tomamos como ponto de partida a equação de crescimento com restrição externa proposta por McCombie e Thirlwall (1994, cap. 7). Como se trata de um modelo já amplamente conhecido será apresentado de forma bastante sucinta. A taxa de crescimento com equilíbrio externo $\left(y_{b}\right)^{3}$ pode ser resumida através da seguinte equação:

$$
\text { (1) } y_{b}=\frac{(1+\eta+\psi)\left(p_{d}-p_{f}-e\right)+\varepsilon Z}{\pi}
$$

\footnotetext{
${ }^{3} \mathrm{O}$ conceito de equilíbrio neste caso refere-se a uma tendência de longo prazo na qual convergem efeitos das decisões de consumo e investimento por parte dos agentes, como também a preocupação do governo com os impactos macroeconômicos do endividamento. Os agentes privados tenderão a investir menos num contexto de déficit externo persistente na medida em que esperam um ajustamento futuro, via aumento dos juros ou via desvalorização da moeda. O governo estará preocupado com o aumento da relação dívida-PIB e uma possível forte contração futura do produto, particularmente se aumenta a desconfiança dos bancos internacionais com relação à capacidade de pagamento do país. Em função disso procurará desaquecer a economia. Ambos os fatores tenderão a alinhar o crescimento do produto com aquele que é consistente com o equilíbrio na balança comercial.
} 
onde $\eta$ é a elasticidade-preço da demanda por exportações $\eta<0$ e $\psi$ é a elasticidade preço da demanda por importação $(\psi<0)$. $P_{d}$ é o preço das exportações em moeda doméstica; $P_{f}$ é o preço das importações em moeda estrangeira; $E$ é a taxa de câmbio e $\mathbf{Z}$ é a renda mundial. As letras minúsculas representam as taxas contínuas de variação das variáveis anteriormente definidas. Finalmente $\varepsilon$ é a elasticidade-renda da demanda por exportação $(\varepsilon>0)$ e $\pi$ é a elasticidade-renda da demanda por importação $(\pi>0)$.

É importante observar que a equação (1) não leva em conta o papel dos movimentos de capital, que permitiriam que a economia mantivesse durante certos períodos taxas de crescimento acima (ou abaixo) da consistente com o equilíbrio na balança comercial. Implicitamente, assume-se que os períodos de endividamento externo e os períodos em que usam divisas para honrar a dívida se cancelam, de forma que o país não poderia crescer com déficit externo de forma permanente. Sem dúvida, os fluxos de capital e os ciclos de liquidez externa podem afetar fortemente o crescimento das economias. Os trabalhos de Barbosa (2001) e Moreno-Brid (2003) oferecem contribuições importantes neste sentido. No entanto, neste artigo, e de forma compatível com o foco assumido no longo prazo, não serão considerados esses efeitos, de modo a manter o foco nos temas da estrutura produtiva e a dinâmica tecnológica.

Adicionalmente, admite-se que é válido o princípio dinâmico de paridade do poder de compra (PPC) e, portanto, que a taxa de câmbio real não se altera no longo prazo. A evidência empírica sugere que os movimentos de longo prazo em preços relativos, medidos em uma moeda única são comparativamente pequenos. De fato, quando surgem variações consideráveis nas taxas de câmbio, os movimentos dos preços domésticos tendem a espelhar tais variações, de modo a manter a taxa de câmbio real relativamente estável (McCombie e Thirlwall, 1994, cap. 3). Alonso e Gracimartin (1998-1999) encontram evidências no sentido que os ajustamentos ao desequilíbrio externo ocorrem principalmente via mudanças no nível de atividade, e não de mudanças nos preços. Algumas evidências empíricas sugerem que no caso do Brasil esse suposto é aceitável (Bertola et al., 2002; Jayme J., 2007; Carvalho e Lima, 2008, 2009; Gouvêa, 2010). Além disso, deve-se observar que ainda no caso em que o princípio de PPP não seja válido, se a soma das elasticidades-preço $(\eta+\psi)$ em módulo não é muito diferente de zero, então o efeito das variações de longo prazo na taxa de câmbio real sobre o crescimento não será significativo (Andersen, 1993). Esse suposto é chave neste tipo de modelos, na medida em que alguns autores consideram o teste decisivo a favor da hipótese de export-led growth (Alonso e Gracimartin, 1998-1999).

A hipótese de PPP permite focar nos temas de estrutura produtiva e tecnologia, cujos efeitos também demoram algum tempo para atuar sobre o crescimento. Assim, a análise a seguir é compatível com esse foco no longo prazo. Sendo válida a versão relativa de PPC a equação (1) reduz-se a: 
(2)

$$
y_{b}=\frac{\varepsilon \mathrm{Z}}{\pi}=\frac{x}{\pi}
$$

A taxa de crescimento com equilíbrio externo é igual à taxa de crescimento das exportações dividido pela elasticidade-renda da demanda por importações. Mas como se altera o modelo simples quando se considera uma economia formada por dois países, centro e periferia? Para responder a essa pergunta, resumimos a seguir o modelo proposto por McCombie e Thirlwall (que na sequência será alterado para incluir a dinâmica do progresso técnico).

O ponto de partida são as identidades keynesianas clássicas, onde o sufixo 1 denota o país Sul e o sufixo 2 o país Norte:

$$
Y_{1}=C_{1}+I_{1}+G_{1}-X_{1}+M_{1}\left(E P_{2} / P_{1}\right)
$$

$\mathrm{e}$

(4) $Y_{2}=C_{2}+I_{2}+G_{2}-X_{2}+M_{2}\left(E P_{1} / P_{2}\right)$

C, I e $G$ denotam o consumo, o investimento e os gastos do governo.Y é a renda nacional, $\mathrm{X}$ e $\mathrm{M}$ representam as exportações e importações, respectivamente, e P indica o nível de preços. Por sua vez, essas variáveis têm um componente exógeno e outro que depende do nível de renda:

$$
\begin{aligned}
& \text { (5) } C_{i}=\bar{C}_{i}+\delta\left(Y_{i}-T_{i}\right) \\
& \text { (6) } T_{i}=\tau Y_{i} \\
& \text { (7) } I_{i}=\bar{I}_{i}+\theta Y_{i} \\
& \text { (8) } G_{i}=\bar{G}_{i}+\zeta Y_{i}
\end{aligned}
$$

Nas equações acima, $i$ pode assumir os valores 1 e $2, \delta$ representa a propensão marginal ao consumo, $T$ é o montante total de impostos, $\tau$ a proporção da renda nacional destinada ao pagamento de impostos, $\theta$ é o acelerador do investimento e $\zeta$ é a resposta do gasto fiscal induzido pela expansão do produto. Uma barra sobre a variável denota o dispêndio autônomo. Considera-se que o gasto autônomo do governo $(\bar{G})$ tem um importante papel na política fiscal e que pode ser controlado em função dos objetivos do crescimento. Essa variável desempenhará um papel importante no modelo dinâmico da próxima seção.

A soma do consumo, do investimento e do gasto do governo pode ser determinado a partir das equações (5), (7) e (8) como: 
(9)

$$
B_{i}=(\delta(1-\tau)+\theta+\zeta) Y_{i}
$$

Substituindo os gastos autônomos, a equação (9) em (3) e expressando o resultado em termos de taxa de crescimento exponencial, obtemos:

(10) $y_{i}=\omega_{A i} a_{B i}+\omega_{B i} b_{i}+\omega_{X i} x-\omega_{M i} m_{i}$

onde $\omega_{A i}$ é a parcela dos gastos autônomos no total da renda do país $i, \omega_{B i}$ a parcela dos gatos induzidos, e $\omega_{X i}$ e $\omega_{M i}$ são a participação das exportações e das importações na renda total, respectivamente. Assumimos que a taxa de câmbio real não se altera no longo prazo $\left(e+p_{2}-p_{1}\right)=0$, ou que os impactos dessas mudanças sobre o crescimento são desprezíveis, em função dos baixos valores das elasticidades-preço da demanda de exportações e importações (ver também nota de rodapé 13).

Considerando os resultados acima e a definição de que o crescimento das exportações de um grupo é igual ao crescimento das importações do outro grupo, o crescimento da renda do primeiro grupo pode ser expresso em termos do crescimento dos gastos autônomos e do crescimento da renda do outro grupo como:

(11) $y_{i}=\alpha_{i} a_{i}+\beta_{i} \pi_{j} y_{j}$

onde

$$
\alpha_{i}=\frac{\omega_{A i}}{\left(1-\omega_{B i}+\omega_{M i} \pi_{i}\right)}
$$

que representa a dinâmica dos gastos domésticos, e

$$
\beta_{i}=\frac{\omega_{X i}}{\left(1-\omega_{B i}+\omega_{M i} \pi_{i}\right)}
$$

que representa o multiplicador do comércio externo. A equação do lócus do equilíbrio no balanço de pagamentos para ambos os países é dada por:

(12) $y_{1}=\frac{\pi_{2}}{\pi_{1}} y_{2}$

A equação (12) explicita o fato de que num modelo de dois países a elasticidade-renda das exportações do país 1 (2) é igual à elasticidade-renda das importações de 2 (1). A seguir, utiliza-se o modelo básico para representar graficamente algumas das interações possíveis entre comércio e política fiscal no modelo básico.

\section{Política fiscal e estrutura produtiva no modelo básico}

Conforme apresentado acima, Raul Prebisch desenvolveu um conjunto de ideias que relacionam o comércio exterior e o crescimento econômico. Essas ideias podem ser discutidas no marco do modelo de dois países proposto por McCombie 
e Thirlwall. Uma vez que há uma tendência de especialização nos países industrializados (país 2) em produtos de alta elasticidade-renda, um aumento na renda da região 1 irá gerar um grande aumento na demanda por produtos da região 2 . Ao contrário, como a região 2 possui uma baixa elasticidade-renda das importações, um aumento de renda na região 2 causará um aumento bem menos significativo na demanda pelos produtos da região 1 .

A Figuras 1 e 2 apresentam uma ilustração estilizada das inter-relações Norte-Sul, onde as variáveis indicadas nos eixos representam as taxas de crescimento do Sul e do Norte $\left(y_{1}\right.$ e $\left.y_{2}\right)$. A curva A (equação 13) proporciona a taxa efetiva de crescimento do Sul, e a curva B (equação 14), a taxa efetiva de crescimento do Norte:

$$
\begin{aligned}
& \text { (13) } y_{1}=\alpha_{1} a_{1}+\beta_{1} \pi_{2} y_{2} \quad \text { (Curva A) } \\
& \text { (14) } y_{2}=\alpha_{2} a_{2}+\beta_{2} \pi_{1} y_{1} \quad \text { (Curva B) }
\end{aligned}
$$

A curva $C C^{*}=0$ (equação 12) corresponde às taxas de crescimento no Norte e no Sul que são consistentes com o equilíbrio externo. Como a especialização do Sul é em commodities de baixa elasticidade-renda, espera-se que $\pi_{2} / \pi_{1}<1$ (o que implica divergência internacional, no sentido que o Norte cresce a taxas superiores ao Sul).

Discutem-se, a seguir, dois cenários possíveis que surgem das seguintes mudanças: (i) aumento na taxa do gasto autônomo no Sul; (ii) uma melhora na competitividade estrutural do Sul. Os efeitos dessas mudanças são apresentados nas Figuras 1 e 2 :

i) Assume-se que, inicialmente, a economia esta em equilíbrio no ponto $z$, conforme a Figura 1. Um aumento do gasto autônomo do Sul (com o objetivo, por exemplo, de atingir metas de pleno emprego) tem como resultado a aparição de um desequilíbrio externo. Se o Norte responde aumentando seu próprio gasto autônomo, então o novo equilíbrio ocorrerá com taxas de crescimento mais elevadas no Norte e no Sul, encontrando um novo ponto de equilíbrio em $g$, conforme a Figura 1. É o caso da expansão coordenada em nível internacional. Se o Norte, no entanto, não muda seu gasto autônomo, então o Sul estará obrigado a reduzir seu gasto e a retornar à posição inicial (McCombie e Thirlwall, 1994, cap. 7). 
Figura 1: Crescimento econômico e gasto autônomo no Norte e no Sul: o caso de um aumento do gasto autônomo no Sul

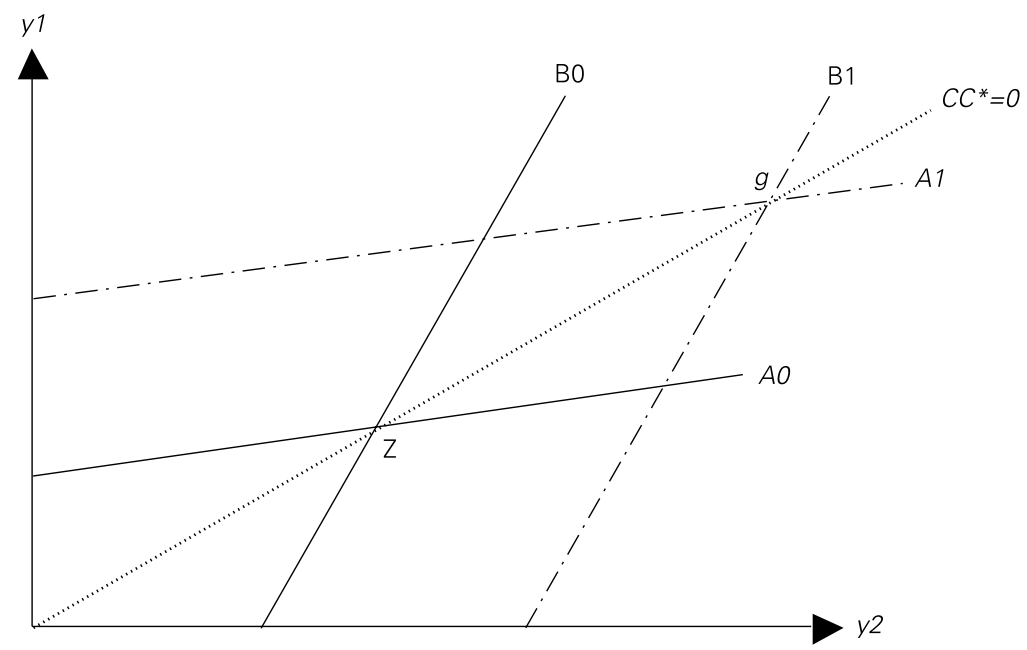

Legenda:

AO - taxa efetiva de crescimento no Sul inicial

B0 - taxa efetiva de crescimento no Norte inicial

A1 - taxa efetiva de crescimento no Sul final

B1 - taxa efetiva de crescimento no Norte final

z - ponto de equilíbrio inicial

$\mathrm{g}$ - ponto de equilíbrio final

$\mathrm{CC}^{*}=0-$ equilíbrio externo

ii) Outra situação surge quando se considera que ocorre uma melhora na competitividade estrutural do Sul (em função, por exemplo, de um processo de catching-up tecnológico, como será estudado na próxima seção), de tal forma que a relação entre as elasticidades muda e a inclinação da curva $C C^{*}\left(\pi_{2} / \pi_{1}\right)$ aumenta. Então, ceteris paribus, o Sul terá gerado um superávit em conta-corrente. A nova estrutura produtiva do Sul desloca a curva $C C^{*}$ para $C C^{* *}$, conforme a figura 2. Mas esse superávit será transitório. Se for válida a ideia de uma reciprocidade implícita, sugerida por Prebisch, então o Sul não deixará de aproveitar as novas oportunidades de crescimento que se abrem. Em lugar de acumular superávits, o Sul vai utilizar as divisas para importar os bens de capital e os insumos requeridos por uma maior taxa de crescimento. Dessa forma, a curva $A 0$ desloca-se para $A 1$; o novo ponto de equilíbrio é obtido em $g$, como demonstrado na Figura 2. Tanto o Sul quanto o Norte crescem agora a taxas mais elevadas do que antes, e a melhora de competitividade do Sul não representa uma ameaça para o Norte. Pelo contrário, ela conduz a taxas mais altas de crescimento nos dois países. 
Figura 2: Crescimento econômico e gasto autônomo no Norte e no Sul: o caso da mudança estrutural no Sul (aumento da relação entre as elasticidades)

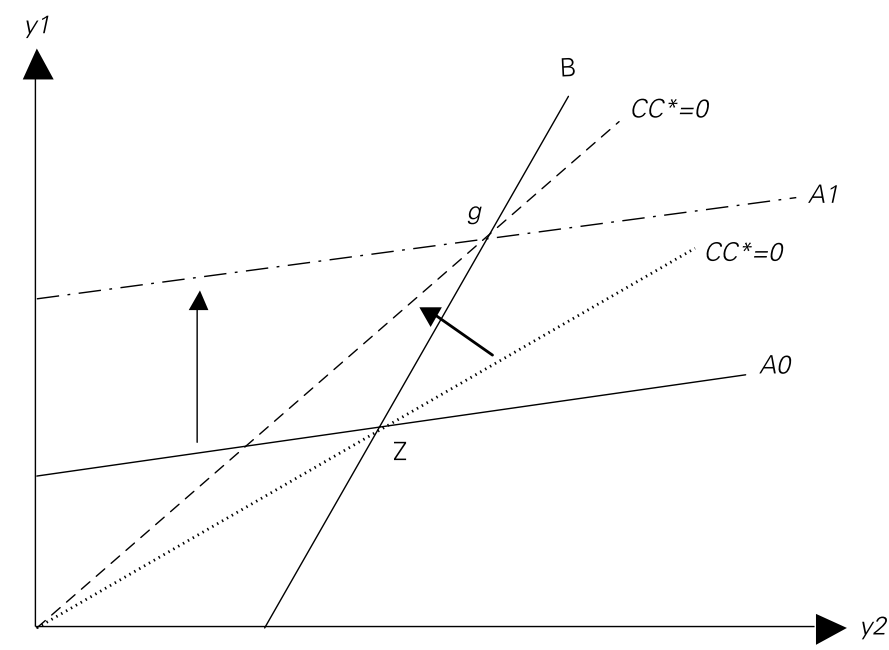

Legenda:

A0 - taxa efetiva de crescimento no Sul inicial

A1 - taxa efetiva de crescimento no Sul final

B - taxa efetiva de crescimento no Norte

z - ponto de equilíbrio inicial

$\mathrm{g}$ - ponto de equilíbrio final

$\mathrm{CC}^{*}=0$ - equilíbrio externo inicial

$C C^{* *}=0$ - equilíbrio externo final (após mudança na relação das elasticidades)

Os resultados anteriores sugerem que a busca de taxas de crescimento mais elevadas não deve negligenciar o papel da mudança estrutural, que torna sustentável a expansão do gasto. As figuras anteriores podem ser interpretadas como uma ilustração da dimensão da mudança estrutural necessária para sustentar uma política fiscal proativa. Outra forma de entender esse resultado é considerar que a política fiscal e a política de mudança estrutural deveriam caminhar juntas, apesar de seus ritmos serem diferentes. Uma política fortemente voltada para a competitividade sem estímulo ao gasto gera superávits, mas não crescimento ${ }^{4}$. Inversamente, uma política que somente aposta na expansão fiscal conduz a uma crise externa no longo prazo (a não ser no caso de uma expansão coordenada).

Um comportamento mercantilista ${ }^{5}$ no Sul, ou uma preocupação forte com possíveis efeitos inflacionários, poderiam fazer com que o Sul não elevasse seu gasto

\footnotetext{
${ }^{4}$ A acumulação de reservas como forma de reduzir problemas de especulação com divisas, ou por previsão em frente aos ciclos no comércio, não implica um viés desfavorável ao crescimento na política.

${ }^{5}$ Define-se como comportamento mercantilista uma situação em que um país procura ampliar sua participação no mercado mundial, gerando saldos positivos na balança comercial, sem um paralelo estímulo ao seu próprio crescimento e às importações. Nesse caso, a expansão do país ocorrerá com um custo para seus sócios comerciais em termos de desequilíbrios externo.
} 
autônomo após a mudança estrutural. Também se o crescimento do Sul fosse limitado por outros fatores não relacionados com a restrição externa, poderiam surgir déficits persistentes no Norte. Se o Norte responde reduzindo seu próprio gasto autônomo, o ponto $z$ já não seria sustentável e os dois países acabariam com taxas de crescimento menores (no ponto $x$ ). A mudança estrutural no Sul não seria, nessas circunstâncias, um motor de crescimento internacional, mas um fator de tensão.

A taxa sustentável de aumento do gasto autônomo no Sul é função das estruturas produtivas e dos padrões de especialização, que definem as elasticidades e que, por sua vez, dependem da dinâmica tecnológica. Na próxima seção essa ideia é formalizada e se mostra qual deveria ser a taxa de crescimento do gasto autônomo no Sul para que o equilíbrio externo seja mantido - a taxa que corresponde à reciprocidade implícita de Prebisch — dada a política industrial e tecnológica do Sul.

\section{PROGRESSO TÉCNICO, ESPECIALIZAÇÃO E DINÂMICA NORTE-SUL}

\section{Modelo com aprendizado tecnológico}

No modelo utilizado na seção anterior a elasticidade-renda das importações é uma variável exógena. Entretanto, conforme mencionado anteriormente, o dinamismo exportador é uma função das capacidades tecnológicas (ver, entre outros, Dosi et al., 1990; Pugno, 1996; Araújo e Lima, 2007; Cimoli, Porcile e Rovira, 2010). Nesse sentido, podemos considerar que as elasticidades-renda das importações são função do hiato tecnológico existente entre os países 1 e 2 . Utilizaremos o mais simples modelo de catching-up usado na literatura, aquele sugerido por Fagerberg $(1988,1994)^{6}$. Esse autor assume que quanto maior for o hiato tecnológico existente entre os dois países (ou seja, quanto mais avançado tecnologicamente for o país 2 em relação ao país 1), maior será a elasticidade-renda da demanda por importações de 1 . Ao mesmo tempo, menor será a elasticidade-renda da demanda de importações de 2. Isso acontece porque o país que dispõe de maior sofisticação tecnológica, nível de diferenciação de seus produtos e capacidade de resposta em frente às mudanças na demanda mundial é também mais capaz de ocupar e ampliar sua participação nos mercados de mais rápido crescimento. Formalmente:

\section{(15) $\pi_{1}=G \gamma$}

onde $\pi_{1}$ é a elasticidade-renda da demanda por importações da região $1, G$ é o gap ou hiato tecnológico existente entre as regiões 1 e 2 (definido com o nível tecnológico do país 2, Norte, sobre o nível tecnológico do país 1, Sul), e $\gamma$ é o coeficiente que relaciona o hiato tecnológico com a elasticidade-renda de importações. Considerar-se-á, para simplificar, que $\pi_{1}$ é uma função linear de $G$ e que $\pi_{2}$ é constante.

\footnotetext{
${ }^{6}$ Uma discussão mais ampla encontra-se em Verspagen (2003), León-Ledesma (2002) e Narula (2004).
} 
A taxa de aumento do hiato tecnológico entre as regiões é definida pela seguinte equação:

$$
g=r-b G
$$

onde $g$ é a taxa de crescimento do hiato $G, r$ é a taxa de progresso tecnológico no país 2 e $b$ é a taxa de "imitação tecnológica" de 1 (periferia ou Sul). Neste caso, estamos supondo que os países periféricos conseguem “imitar” (catching-up) a tecnologia desenvolvida no centro a uma velocidade que depende de $b$. Esse último parâmetro representa os esforços de Pesquisa e Desenvolvimento (P\&D), o nível de capital humano e a infraestrutura em ciência e tecnologia, que definem a capacidade de cada país de imitar e absorver a tecnologia da fronteira (Lundvall, 1992; Freeman, 1995).

Por sua vez, a taxa de crescimento do gasto autônomo do país 1 é explicitada pela seguinte equação:

$$
\hat{a}=\zeta\left(\frac{\pi_{2}}{\gamma G} y_{2}-\left(\alpha_{1} a_{1}+\beta_{1} \pi_{2} y_{2}\right)\right)
$$

A equação anterior garante que em equilíbrio o princípio da reciprocidade implícita será válido: a periferia sempre aumentará o gasto autônomo na medida necessária para que todo o potencial de crescimento (cujo limite é a restrição externa) seja aproveitado. Cada vez que a taxa de crescimento efetiva (equação 13) for inferior à taxa de crescimento com equilíbrio externo (equação 14), o país aumentará a taxa de crescimento do gasto autônomo. Adicionalmente, assumir-se-á que o crescimento do Norte é uma constante, o que simplifica bastante a análise. Fazendo isso, perdemos uma dimensão importante da interação Norte-Sul, a saber, a capacidade do Sul de estimular a demanda por produtos do Norte. Mas, ao mesmo tempo, esse suposto permite concentrar a atenção em outro aspecto de interesse: a relação entre as estruturas produtivas e o espaço disponível para a política fiscal.

As equações (16) e (17) geram um sistema dinâmico cuja matriz jacobiana é:

$$
\mathbf{J}=\left[\begin{array}{cc}
0 & -b \\
-\zeta \alpha_{1} & -\zeta \frac{\pi_{2} y_{2} \gamma}{(\gamma G)^{2}}
\end{array}\right]
$$

Assim, temos:

$\operatorname{Tr}[\mathrm{J}]=0-\zeta \frac{\pi_{2} y_{2} \gamma}{(\gamma G)^{2}}<0$

$\operatorname{Det}[\mathrm{J}]=0-\left(-\zeta \alpha_{1}\right)(-b)=\zeta \alpha_{1} b$

O sistema dinâmico apresenta como resultado um equilíbrio de ponto sela, que é instável. Isso sugere que o governo tem uma delicada tarefa na administração da 
política fiscal e no controle de expansão do gasto público de acordo com os limites impostos pela competitividade externa, para evitar fenômenos de marcadas flutuações no crescimento.

Determinaremos agora os valores de equilíbrio de $G, a_{1}$ e $y_{1}$. No equilíbrio temos, $g=0$ e $\hat{a}_{1}=0$ e portanto:

(19) $G=\frac{r}{b}$

(20) $a_{1}=\frac{1}{\alpha_{1}}\left[\frac{\pi_{2}}{\gamma G} y_{2}-\beta_{1} \pi_{2} y_{2}\right]$

ou $a_{1}=\frac{1}{\alpha_{1}}\left[\frac{\pi_{2} b}{\gamma r} y_{2}-\beta_{1} \pi_{2} y_{2}\right]$

Usando os valores de equilíbrio na equação (12), temos:

(21) $y_{1}=\frac{\pi_{2} b}{\gamma r} y_{2}$

A partir dos resultados anteriores, é possível realizar alguns exercícios de dinâmica comparativa para analisar os efeitos, sobre o hiato e a expansão fiscal em equilíbrio, de choques nos parâmetros tecnológicos e de demanda.

\section{Dinâmica comparativa}

A Tabela 1 mostra as derivadas parciais dos valores de equilíbrio com relação a alguns dos parâmetros do modelo, a partir das equações (19), (20) e (21).

Tabela 1: Matriz de derivadas parciais

\begin{tabular}{|c|c|c|c|c|c|}
\hline & \multicolumn{4}{|c|}{ Parâmetros } \\
\hline & & $\begin{array}{l}\text { b (taxa de } \\
\text { imitação } \\
\text { tecnológica) }\end{array}$ & $\begin{array}{l}r \text { (taxa de } \\
\text { progresso } \\
\text { tecnológico } \\
\text { no Norte) }\end{array}$ & $\begin{array}{l}y_{2} \text { (taxa de } \\
\text { crescimento do } \\
\text { produto no Norte) }\end{array}$ & $\begin{array}{l}p_{2} \text { (elasticidade- } \\
\text {-renda das } \\
\text { importações } \\
\text { do Norte) }\end{array}$ \\
\hline \multirow{3}{*}{ 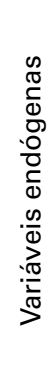 } & $\begin{array}{l}\text { G } \\
\text { (HIATO } \\
\text { TECNOLÓGICO) }\end{array}$ & $-\frac{r}{b^{2}}$ & $\frac{1}{b}$ & 0 & 0 \\
\hline & $\begin{array}{l}a_{1} \text { (gasto } \\
\text { autônomo) }\end{array}$ & $\frac{1}{\alpha_{1}}\left[\frac{\pi_{2} y_{2}}{\gamma r}\right]$ & $-\frac{1}{\alpha_{1}}\left[\frac{\pi_{2} b}{\gamma r^{2}} y_{2}\right.$ & $\frac{1}{\alpha_{1}}\left[\frac{\pi_{2} b}{\gamma r}-\beta_{1} \pi_{2}\right]$ & $-\frac{1}{\alpha_{1}}\left[\frac{b}{\gamma r} y_{2}-\beta_{1} y_{2}\right.$ \\
\hline & $\begin{array}{l}y_{1} \text { (taxa de } \\
\text { crescimento } \\
\text { do produto } \\
\text { no Sul) }\end{array}$ & $\frac{\pi_{2}}{\gamma r} y_{2}$ & $-\frac{\pi_{2} b}{\gamma r^{2}} y_{2}$ & $\frac{\pi_{2} b}{\gamma r}$ & $\frac{b}{\gamma r} y_{2}$ \\
\hline
\end{tabular}


Vários resultados emergem dessa tabela. Um deles era esperado, a saber, que o hiato tecnológico de equilíbrio aumenta quando o Norte aumenta sua taxa de inovação $(r)$ e diminui quando o esforço tecnológico do Sul $(b)$ aumenta. Mas o que resulta mais interessante é a relação entre as duas políticas - fiscal e tecnológica - explicitada pelo modelo.

Com efeito, a taxa de crescimento do gasto autônomo em equilíbrio $\left(a_{1}\right)$ aumenta quando aumenta o esforço tecnológico do Sul (b): na medida em que a restrição externa é menos severa, há mais espaço para uma expansão sustentável do gasto. Da mesma forma, choques positivos exógenos na taxa de crescimento do resto do mundo $\left(y_{2}\right)$, ou na propensão do mundo a importar produtos da periferia $\left(p_{2}\right)$, abrem oportunidades para a adoção de uma política fiscal favorável ao crescimento. É importante ressaltar que $\frac{1}{\gamma G}>\beta_{2}$ : essa é uma condição necessária para que o valor do hiato tecnológico em equilíbrio seja positivo. Sendo assim, a taxa de aumento do gasto autônomo responderá positivamente ao crescimento da renda mundial e da propensão a importar do resto do mundo. A magnitude dos diferentes efeitos pode ser observada na matriz de derivadas parciais na Tabela 1.

Em resumo, mudanças na demanda mundial (via aumento de $p_{2}$ ou via aumento de $y_{2}$ ) assim como uma política tecnológica mais ativa (aumento de $b$ ) promovem o crescimento. Mas não se deve esquecer que esse resultado considera que a taxa de aumento do gasto autônomo está em equilíbrio. Para que seja válido é necessário que a política fiscal responda positivamente às melhoras na competitividade internacional do país — ou seja, que seja evitado o cenário "mercantilista”, como definido na nota 5 .

\section{CONCLUSÕES}

O trabalho tomou como ponto de partida algumas ideias pioneiras de Raul Prebisch sobre cooperação internacional e sobre a importância da coordenação num sistema formado por países cujas estruturas produtivas e capacidades tecnológicas são fortemente assimétricas. Essas ideias foram formalizadas através de um modelo de crescimento de dois países com restrição externa. Nele foi incluída uma nova função definindo o comportamento das elasticidades-renda de exportação e importação. Esse comportamento depende de um processo de catching-up do qual surge o valor do hiato tecnológico em equilíbrio. Assim, crescimento, restrição externa, elasticidades e dinâmica do hiato tecnológico são analisadas conjuntamente. A dinâmica do aprendizado afeta a competitividade internacional e o crescimento sustentado no longo prazo.

A relação entre as elasticidades é definida pelo padrão de especialização. A mudança estrutural e o aprendizado são as forças subjacentes que redefinem esse padrão. Trata-se de um processo complexo sujeito a retornos crescentes e path-dependecy, de tal forma que podem surgir círculos virtuosos (ou viciosos) de alto (baixo) crescimento e competitividade. É também por essa razão que as políticas 
tecnológicas são tão importantes para corrigir trajetórias de crescimento que são fortemente inerciais.

Por outro lado, esse resultado não implica que as políticas fiscais não sejam importantes para o crescimento. Com efeito, apenas a expansão das exportações não sustenta o crescimento, se não há, paralelamente, um aumento da demanda interna e do gasto autônomo, com um papel-chave para a política fiscal. Assim, o modelo destaca a interação entre dois aspectos do processo de crescimento que muitas vezes se analisam de forma separada, mas que se condicionam mutuamente. Por um lado, existe um limite para as políticas fiscais keynesianas no Sul quando a restrição externa é muito forte e o hiato tecnológico Norte-Sul, muito elevado. Nessa situação, tentativas de sustentar a expansão do produto apenas com o gasto público estão fadadas a esbarrar na restrição externa. Ao mesmo tempo, uma política voltada exclusivamente para a competitividade internacional pode gerar resultados negativos para o próprio país que as aplica. Políticas com foco apenas na tecnologia podem elevar o desemprego, sem aumentar a taxa de crescimento. Em particular, se o resto do mundo adotar políticas fiscais restritivas para corrigir seu próprio desequilíbrio externo com o país “mercantilista”, então pode haver uma queda da taxa de crescimento de todos os países.

Um corolário dessa interação é que, nas economias periféricas, o espaço para as políticas fiscais é em parte criado pelas políticas industrial e tecnológica. O modelo permite encontrar a taxa em que deveria crescer o gasto autônomo para manter o princípio de reciprocidade implícita funcionado (importações iguais às exportações periféricas) e para maximizar o potencial de crescimento do Sul, dada a restrição externa. Na medida em que o equilíbrio do sistema é um ponto sela, a gestão da política fiscal aparece como um desafio complexo, que deveria ser visto em conjunto com medidas de mais longo prazo destinadas a elevar a elasticidade-renda das exportações do Sul.

\section{REFERÊNCIAS BIBLIOGRÁFICAS}

AMSDEN, A. (1989) Asia's Next Giant: South Korea and Late Industrialization, New York, Oxford University Press.

ALONSO, J.A. e GRACIMARTÍN, C. (1998-1999) "A new approach to balance-of-payments constraint: some empirical evidence”, Journal of Post-Keynesian Economics, v. 21, n.2, pp. 259-282.

ANDERSEN, P.S. (1993) “The 45o applied rule”, Applied Economics, v. 25. pp. 1279-1284.

ARAÚJO, R.A. e LIMA, G.T. (2007) "A structural economic dynamics approach to balance-of-payments-constrained growth”, Cambridge Journal of Economics, Setembro, 31, pp. 755-774.

BARBOSA FILHO, N. (2001) "The balance-of-payments constraint: from balanced trade to sustainable debt”, Banca Nazionale de Laboro Quaterly Review, v. 54, n. 219, pp. 381-400.

BELL, M. (2006) "Time and technological learning in industrialising countries: how long does it take? How fast is it moving (if at all)?", International Journal of Technology Management, vol. 36, No. 1-3, pp. 25-39.

BERTOLA, L., HIGACHI, H. e PORCILE, G. (2002) "Balance-of-payments constrained growth in Brazil: A test of Thirlwall's law, 1890-1973”, Journal of Post-Keynesian Economics, v. 25, n.1, pp. 123-140. 
CARVALHO, V. e LIMA, G.T. (2008) "Macrodinâmica do produto e da renda sob restrição externa: A experiência brasileira no período 1930-2004”, Economia Aplicada, v. 12, n. 1, pp. 55-77.

CARVALHO, V. e LIMA, G.T. (2009) "A restrição externa e a perda de dinamismo da economia brasileira: Investigando as relações entre estrutura produtiva e crescimento econômico", Economia e Sociedade, v. 18, n. 1, pp. 31-60.

CIMOLI, M., G. DOSI e STIGLITZ J. (eds.) (2010), Industrial Policy and Development, The Political Economy of Capabilities Accumulation, Oxford, Oxford University Press.

CIMOLI, M. e PORCILE, G. (2009) "Sources of learning paths and technological capabilities: An introductory roadmap of development processes”, Economics of Innovation and New Technology, 1476-8364, v. 18, Issue 7, 2009, pp. 75-694

CIMOLI, M., PORCILE, G. e ROVIRA, S. (2010) "Structural convergence and the balance-of-payments constraint: Why did Latin America fail to converge", Cambridge Journal of Economics, v. 34, n. 2, Março, pp. 389-411.

DOSI, G., PAVITT, K. e SOETE, L. (1990) The Economics of Technical Change and International Trade. Brighton: Wheatsheaf.

FAGERBERG, J. (1988) “International competitiveness”, Economic Journal, v. 98, 355-374.

FAGERBERG, J. (1994) “Technology and international differences in growth rates”, Journal of Economic Literature, v. 32, 1147-1175.

FEEMAN, C. (1995) “The National System of Innovation in Historical Perspective”, Cambridge Journal of Economics, v. 19, pp. 5-24.

GOUVÊA, R.R. (2010) "Padrão de especialização produtiva e crescimento econômico sob restrição externa: Uma Análise Empírica”, Dissertação de Mestrado, FEA-USP, São Paulo.

JAYME Jr., F.G. (2007) “Growth under external constraint in Brazil: A post-Keyneisan approach”, in Holt, R. e Pressman, S. (eds.) Empirical Post-Keyneisan Economics: Looking at the Real World, Nova York: M.E Sharp, pp. 305-328.

LEÓN-LEDESMA, M.A. (2002) "Accumulation, innovation and catching-up: an extended cumulative growth model”, Cambridge Journal of Economics, v. 26, pp. 201-216.

LUNDVALL, B.A. (1992) National Systems of Innovation: Towards a Theory of Innovation and Interactive Learning. Londres: Pinter.

MORENO-BRID, J.C. (2003) "Capital flows, interests payments and the balance-of payments constrained growth model: A theoretical and empirical analysis”, Metroeconomica, v. 54, n. 2, pp. 346-365.

MCCOMBIE, J.S.L. e Thirlwall, A.P. (1994) Economic Growth and the Balance of Payments Constraint. New York: St. Martin Press.

NARULA, R. (2004) "Understanding absorptive capacities in an innovation systems context: Consequences for economic and employment growth", DRUID Working Paper n. 04-02, December.

OCAMPO, J.A. (2005) "Raúl Prebisch y la agenda del desarrollo en los albores del siglo XXI". Revista de la CEPAL, v. 75.

PREBISCH, R. (1963) Hacia una Dinámica del Desarrollo Latinoamericano. México: Fondo de Cultura Económica.

PREBISCH, R. (1981) Capitalismo Periférico: Crisis y Transformación. México: Fondo de Cultura Económica.

PUGNO, M. (1996) "A Kaldorian model of economic growth with labour shortage and major technical changes", Structural Change and Economic Dynamics, v. 7, pp. 429-446.

RODRÍGUEZ, O. (1977) "Sobre la concepción del sistema centro-periferia”, Revista de la CEPAL, First Semester.

RODRÍGUEZ, O. (1980) La Teoría del Subdesarrollo de la CEPAL. México: Siglo XXI.

RODRÍGUEZ, O. (2007) El Estructuralismo Latinoamericano. México: Siglo XXI.

VERSPAGEN, B. (1993) Uneven Growth Between Interdependent Economies. Avebury: Aldershot. 